\title{
NIÇARDS A LA MALLORCA BAIXMEDIEVAL ${ }^{1}$
}

\author{
MARIA BARCEló I CRESPI \\ Universitat de les Illes Balears
}

\author{
SUMARI
}

El col.lectiu de niçards a Mallorca.- 2. Relacions comercials.- 3. Apèndix.

L'illa de Mallorca, enmig de la conca de la Mediterrània occidental i no massa allunyada de les costes de la península Iberica, de la península Itàlica, del Sud de França o del Nord d'Africa serà testimoni del pas de navegants, especialment mercaders, que des de l'Antiguitat han anat creuant el Mare Nostrum, amb les repercussions que aquest fet ha pogut aportar a la vida de l'illa a nivell econòmic, social i cultural, sobretot. El paper de cruillla dins el concert mediterrani es mantindrà fins els nostres dies encara que els anys li hagin conferit uns valors $\mathrm{i}$ unes funcions diferents. La condició de port important exercirà una influencia extraordinària en la vida de la ciutat de Mallorca i de l'illa.

Pel que fa a la Baixa Edat Mitjana, el comerç constituirà una de les activitats economiques fonamentals. No és extrany, ido, que per una banda a Mallorca recalin mercaders de molt diverses procedencies per damunt de tot de l'àmbit mediterrani, però sens descuidar els castellans o portuguesos entre altres i que, per altra banda, les relacions comercials siguin força intenses.

\footnotetext{
'Abreviatures i sigles utilitzades: $A H=$ Arxiu Históric; $A R M=$ Arxiu del Regne de Mallorca; EU = Extraordinadi d'Universitat; $L R=$ Lletres Reials; Prot $=$ Protocol; $R P=$ Reial Patrimo$\mathrm{ni} ; \mathbf{S U}=$ Suplicacions.

"Anuario de Estudios Medievales", 24 (1994)
} 
Es en aquest context on hem de situar les relacions entre Mallorca i Niça i la presencia d'un col.lectiu niçard a l'illa.

\section{El COl.Lectiu de niçards a Mallorca}

Tot i no ser tant nombrós o destacat com alguns d'italians, en especial Genova o Venecia, Niça comptava amb un consolat a la ciutat de Mallorca la qual cosa és significativa de la re

lació comercial existent entre ambdós indrets ${ }^{2}$. Els consols no sempre eren del país que representaven sinó que ben bé podien ser mallorquins de reconegut prestigi professional o social. L'abast geografic de la seva competencia podia ser la Ciutat o també l a illa de Mallorca. En la majoria d'ocasions, l'actuació dels consols tenia per objecte defensar els interessos comercials dels seus representats tot $\mathrm{i}$ que ja el 1233 Jaume I havia autoritzat als consols genovesos a administrar justícia en els temes d'índole civil. Val a dir que sovint el consol no sols defensava els interessos de Niça estricta sinó també de la localitat de Vilafranca de Niça. Coneixem els noms de Guillem Castellar, notari, anomenat el 16 d'octubre de 1424, Antoni Sastre, mercader qui ja ostentava tal càrrec abans de 1469 perque a partir d'aquesta data va tenir lloc el nomenament de Joan Rosató, també merceder; Bartomeu Cunilleres àlias Pacs, ciutadà, el 1476; Bartomeu Pacs [tal vegada és el mateix que l'anterior] el 1491.

En el cas de les illes de Menorca o Eivissa un mateix consol podia aunar dues o més representacions: el 18 de desembre de 1496 una carta reial datada a Burgos dirigida al lloctinent $i$ altres oficials reials en la illa $i$ vila d'Eivissa informava que en el dia present $i$ per privilegi reial el rei proveïa i feia gràcia i mercè a l'escrivà Joan Serralonga de l'ofici de consolat de genovesos i niçards, vacant per mort de mestre Antoni Cristofol, en la vila i illa d'Eivissa. Manava lliurassin possessió pacffica del dit càrrec $i$ qui no obés cauria $i$ incorreria en ira $i$ indignació reial aixı com en pena de 1.000 florins d'or d'Aragó dels béns de qualsevol contrafaent aplicadors als cofres reials ${ }^{3}$. Anys més tard, del 5 de juny de

\footnotetext{
${ }^{2}$ Pau CATEURA Bennasser, Consolats estrangers a les Illes Balears (1347-1500, "Mayurqa", 22-I (1989), pp. 167-180.

'ARM, LR, 79, fols. 188 r-188 v.
} 
1516, es coneix una carta de la reina, datada a Madrid el 17 d'abril passat, dirigida al lloctinent a qui informava que a la vegada manàs al governador d'Eivissa que restituls a Bernat Nicolau en la possessió que tenia de l'ofici de consol de niçards en la dita illa. Afegia que se li reposàs el sou i altres drets. L'havia desposseït un tal Pedro Tur qui ara el regentava. El manament de la reina insistia en que es mantingués Nicolau fins que es fes justícia y hoides les parts se provea en ello otra cosa.

Pere Serra el 1500, per a Menorca, ostentava la delegació de distints països o ciutats $i$ entre elles Niça.

El conjunt de niçards a Mallorca no era el més nombrós entre els col.lectius extrangers pero no per aixo menys interessant. Gabriel Llompart indica que els mercaders de Niça apareixen amb freqüencia cap a mitjans segle XV en el port de Palma i entre ells esmenta a Jordi Andreu, patró de nau (1441), Joan de Litardi, mercader (1443), Rafel Carle, mercader (1465), Joan Vayrat (1470) entre altres. No obstant, el mateix autor fa referencies a un document on apareix una llista de mariners estrangers, datat el 1445, que habitaven a la ciutat de Mallorca on s'aprecia una procedencia molt diversa $i$ entre els quals destacaven els mediterranis perd, curiosament, no esmenta els niçards ${ }^{5}$.

La majoria es dedicaven al quefer mercantívol $i$ alguns fins $i$ tot fixaren la seva residencia de manera definitiva a la Ciutat de Mallorca.

Un cas clar és el d'Antoni del Poso. El 13 de setembre de 1490 els jurats de la Universitat de la ciutat i Regne de Malorca escrivien als receptors, administradors, col.lectors i compredors de qualsevol drets, imposits, vectigals, ajudes $i$ talles en el present Regne comunicant-lis que per la potestat que els havia atribuiit el Gran i General Consell celebrat el dia 7 del mes d'agost de 1488 havien admes com a novell pobledor a mícer Antoni del Posso, niçard que havia decidit "transportar asi en la dita present Ciutat y constituhir son domicili e pendra muller en aquella si empero li sarà donada y atorguada franquesa de prevera per temps de deu anys". Efectivament, haguda informació verídica de la bona fama, vida, $e$ conversacio y fecultats els jurats li concediren la dita franquesa que entraria

\footnotetext{
${ }^{4} A R M, L R, 83$, fols. 244 r-245 r.

sGabricl LLOMPART, La pintura medieval inallorquina. Su entorno cultural y su iconografia, I, Palma, 1977, pp. 89 i 206.
} 
en vigor després d'haver pres muller. Aquesta exempció contemplava que ell, muller, famflia $\mathrm{i}$ béns fossin francs envers alguns impostos com el quint de vi, sisa de les carns, molitja, segell del drap, vectigals, imposicions i altres drets de la mateixa manera que ho eren els preveres, aixd si, sols per deu anys. S'exceptuava, empero, aquelles contribucions molt necessàries com per a adops de murades, ajudes de blats, manaments d'aigües, donatius als reis $\mathrm{i}$ als infants en els quals sia tengut peguar $e$ contribuir com los altres habitadors ${ }^{6}$. Les anomenades franqueses de prevere afavorien a aquells de fora que establien la seva residencia acr. Aquest niçard degué morir el 1508 perque del 28 de març d'aquest any coneixem el seu inventari fet pel prevere Lluís Berard, curador del seu fill i hereu Jaume Joan del Posso?. Vivia a la illeta de la gabella de la sal, a la parroquia de Santa Creu, en una casa que sembla que era de l'esmentat mossen Lluís Berard. Perd, tal vegada el niçard més conegut per als mallorquins hagi estat Pere. El famós pintor Pere Niçard està documentat a Mallorca entre 1468 i 1470 en que pintà el celebre retaule de Sant Jordi, avui conservat al Museu Diocessà de Mallorca i se'l relaciona, és clar, amb la colonia dels nissards i francesos que hi havia a l'illa. La part que queda del retaule representa un Sant Jordi armat $i$ muntat en un cavall blanc clavant la llança en la boca del dragó. Al fons reprodueix una ciutat de la qual per tota una serie de dades toponimiques i geografiques es sap que correspon a la ciutat de Mallorca medieval. Es tracta d'una de les obres més importants del gotic flamenc illenc en que la minuciositat i fidelitat al paisatge son les característiques bàsiques ${ }^{8}$.

\footnotetext{
${ }^{6}$ ARM, EU. 19, fol. $11 \mathrm{r}$.

En el marge d'aquest document, amb lletra diferent i escrita amb posterioritat, es pot llegir la curiosa nota que diu així: "Lo fill de aquest mícer Antoni se diu míser Jaume del Posso y vuy cardinal y persona preheminentíssim en la cort romana nat y criat en Mallorca cs ee feta la present nota al primer de maig de 1561. Joan Calaphat notari scrivà de la present Universiatat. Dit cardinal per poc animo dexa d'esser Papa y finalment mor' havent fet molt poc be a mallorquins si no fone an en Barbut Ferragut que feu canonge".

${ }^{7}$ ARM, Prot. T-497, fols. 53 v-61 v.

'Gabriel Llompart, Ob. cit.
} 


\section{RELACIONS COMERCIALS}

La relacio comercial amb el Sud de l'actual França ve d'enrera. Tal vegada, pero, per al cas de Niça el trànsit intens vendria en el segle XV i potser més a la segona meitat i primers anys de la centúria següent. AixI, sembla que a partir de les llicencies que es concedien a vaixells per anar a mercadejar a finals del segle XIII no consten referències a Niça ${ }^{9}$. Per altra banda, segons Marcel Durliat i Joan Pons a la primera meitat del segle XIV el port de la ciutat de Mallorca rebia naus procedents de diversos punt del litoral mediterrani francès, aix $\delta$ si molt més poques que italianes, com Narbona Agde, Aigues-Mortes entre els més destacats pero no esmenten Niça ${ }^{10}$.

En opinio de Pierre Macaire, Niça no va ser un port molt important perque la pobresa i la infertilitat de l'indret, entre altres aspectes, no li permetien convertir-se en una plaça comercial destacada $i$ només la reexportació podia procurar al seu port un poc d'activitat. Aquest autor ha estudiat el comerç a la primera meitat del segle XV i comenta que Mallorca sovint s'unia a Niça via Eivissa per raó d'importants entregues de sal fetes per a la ciutat provençal. Afegeix que amb dades procedents de registres del notari Antoni Contestr $i$ per als anys 1403-1438 es constata un número total de 31 relacions, essent l'any 1438 el de major nombre: sis naus castellanes, una niçarda $i$ un navili noliejat per un florentr. Les naus que unien els dos ports, Mallorca-Niça o Vilafranca, no sempre eren dels llocs de procedencia $i$ podien continuar fins a Itàlia cap a Saona o Génova" ${ }^{11}$.

Per la seva banda Carme Batlle tampoc fa referencia a Niça en l'interessant $\mathrm{i}$ ben documentat treball sobre la presencia de mercaders francesos en els territoris catalano-aragonesos ${ }^{12}$.

\footnotetext{
"Antoni RIERA MEUS, La "llicencia per a barques" de 1284, una font important per a l'estudi del comers exterior mallorquí del darrer quart del segle XIII, "Fontes Rerum Balearium", III (1980), pp. 121-140.

${ }^{10}$ Marcel DURLAT i Joan PONS I MARQUES, Recerques sobre el moviment del port de Mallorca en la primera meitat del segle XIV, "VI Congrés d'Història de la Corona d'Aragó", Madrid, 1959, p. 351.

"Pierre MACAIRE, Majorque el le cominerce intemational (1400-1450 environ), Lille, 1986, pp. 505-508.

${ }^{12}$ Carme BATLle I GALlaRT, Els fiancesos a la Corona d'Aragó, "Anuario de Estudios Medievales", 10 (1980), pp. 361-392.
} 
En la relacio de noliejaments de naus oferit per Onofre Vaquer a partir de notícies marítimes extretes dels protocols dels notaris Bernat Contestl $\mathrm{i}$ Joan Castell on es troben no sols noliejaments sino tambe assegurances, comandes i reconeixements de deutes per viatges, desde 1450 a 1499, sols consta la referència a un balener anomenat Sant Andreu patronejat per Andreu de Niça amb 16 homes que el 1480 prengue destr cap a Trapena. Les naus que sortien del port de Mallorca, entre destins finals i ports d'escala, en la documentacio consultada per aquest autor, els ports francesos representaven 1'3\% front, per exemple, al 9'5 de Napols, 9'4 de Sardenya, 6'7 de Sićlia o 23'1 de Barbaria. Els ports francesos que documenta eren Niça, Agde, Narbona i Aigues-Mortes, per aquest ordre. Curiosament no cita Marsella perque no era un port comercial actiu el qual no s'incorporà a França fins el $1481^{13}$.

En aquesta recerca basicament hem analitzat dades a partir de tres tipus de documents ben concrets: assegurances i certificatories de forment per una banda $i$ concessions de guiatges per altra banda. La manca de cereals a la Mallorca baixmedieval era un mal gairebe endemic. A l'administració pública li competia els contactes amb els mercaders, o be els estímuls a la importació en el cas de què aquesta no estàs suficientment garantida. En els anys de fretura, que eren freqüents, l'objectiu immediat era aconseguir la llicència d'exportació coneguda amb el nom de treta la qual era atorgada pel monarca prèvia solicitud per part d'agents o influents personalitats mallorquines que anaven en expressa missio a la Cort per aixo. Quan s'havia aconseguit la llicencia i davant la necessitat de comprar cereals, especialment blat, la Universitat incentivava la importacio $i$ concedia una prima denominada ajuda la quantia de la qual la fixava el General Consell o bé una comissió delegada a l'efecte. La Universitat tenia el deure de pagar la prima una vegada que l'importador hagués complimentat l'entrega del cereal en el termini convengut, acte que es justificava mitjançant un albarà conegut com a certificatoria. En dits albarans, constaven, en general, el nom del consignatari a Mallorca a qui anava dirigida la mercaderia, el tipus d'embarcacio, el propietari i/o patro

\footnotetext{
${ }^{13}$ Onofre VAQUER, La navegació mallorquina a l'època del Descobriment, "Les Illes Balears i América",I, Palma, 1992, p. 341.

Vegeu també: Onofre VAQUER, El comerç marítion de Mallorca a la segona meitat del segle XV, "Randa", 29 (1991), pp. 105-119; IDEM, Coiners $i$ capizal mercantil a Mallorca (1448-1480), "La mediterrènia. Antropologia i història", Palma, 1990, pp. 161-172.
} 
de la mateixa que la majoria de vegades coincidien, la procedencia, la quantitat de cereal i les seves condicions (qualitat, grau de puresa), la quantia de la prima, etc.

Tots o part d'aquests detalls en relació al comerç amb Niça i la seva àrea o simplement a niçards es oden veure a través d'alguns exemples ben concrets:

El 13 d'octubre de 1493 Pere Segur de la vila de Pollença reconeixia a Dionisio Staller, mercader de Vilafranca de Niça pero ara resident en aquella vila mercantiliter, haver rebut 245 quarteres de forment de xeixa de França i 128 quarteres de forment roig no porgades tambe de França. Una de les persones que actuaven com a testimoni també era un niçard, Matxi Marti'14.

Del 26 de febrer de 1506 data la certificatoria de que Cosme de Cosi, genoves, havia descarregat de la barca patronejada per Honorat Genovard, niçard, 1.742 quarteres de forment brut que resultaren 1.497 de net. Se li pagaren el 2 de març 149 lliures, 15 sous i 3 diners en concepte d'ajuda a rao de 2 sous per quartera ${ }^{15}$.

Jeroni Colomines el dia 9 de setembre de 1507 dirigia un escrit als jurats en el que feia constar que de la barca de Joan Miquel Infant la qual arribà de Niça el 28 del passat mes d'agost, s'havien descarregat 118 quarteres d'ordi brut. Una vegada fet l'assaig, és a dir, llevat les impureses, havien quedat 110 quarteres, 5 barcelles i 4 almuds. El preu de l'ajuda s'havia establert en 1 sou i 3 diners per quartera la qual cosa es converts en un total de 6 lliures, 18 sous i 8 diners ${ }^{16}$.

Les certificatories de descàrrega de forment $i$ altres cereals es lliuraven a efectes de poder percebre la quantitat oferida com a ajuda. El 12 de novembre de 1507 consta que del navili de Jaume Barber, el qual arribà de Niça el 5 del mateix mes, Bernat Busquets havia descarregat 126 quarteres i 5 barcelles d'ordi brut (116 quarteres i 3 barcelles net). L'ajuda

\footnotetext{
. ${ }^{14}$ ARM, Prot. P-388, fols. 78 r-78 v.

isARM, EU, 24, fol. 107 r.

${ }^{10} \mathrm{ARM}, \mathrm{EU}, 25$ fol. $181 \mathrm{v}$.

Joan Miquel Infant era nissard de Vilafranca. Obra una altra referència de descarrega de forment datada el dia 20 de marc de 1507 (ARM, EU, 25, fols. 33 r-33 v.).
} 
muntà a 8 lliures, 14 sous i 8 diners, a rao de 1 sou i 6 diners per cada quartera ${ }^{17}$.

A Julià Ballester i a Antoni de Niça, majorals dels Barlier, s'havien de pagar 37 lliures i 12 sous per descàrrega de 6.274 quarteres de forment i altra quantitat a més per la descarrega de la barca dels germans Alexandro i Bernardo Galleti i del carreco de Bernardo Fischo tramès per Carles Despuig, ambaixador per al forment per la present Ciutat i lliurades als administradors elets per la Universitat pel que feia al negoci del forment. La data de la certificatoria és del 6 de novembre de $1507^{18}$.

De la barca de Nardo Durmeya, arribada de Niça dia 4 de gener de 1508 , es certificava quatre dies després que el pellisser mestre Nicolau Neo havia descarregat 23 quintars de farina que equivalia a 19 quarteres i 1 barcella. L'ajuda que calia percebre va muntar 2 lliures, 7 sous i 6 diners. De la mateixa barca sis dies després Francisco Durmeya descarregava certa quantitat d'ordi que resultaren ser en net 46 quarteres i 4 barcelles cobrant la corresponent ajuda ${ }^{19}$.

El 4 de gener de 1510 es feia constar com de la barca del genoves Batista Spindola, arribada de Niça el dia 11 del passat mes de desembre, Paulo Galean, niçard, havia desembarcat 102 quarteres de forment net que a rao de 1 sou per quartera d'ajuda muntà 5 lliures i 2 sous. El dia 6 de febrer eren 102 quarteres de forment. El dit Paulo demanava alegrar-se, 0 sia, obtenir algunes garanties de l'ordre que fos i "per ço los dit magnifichs jurats en testimoni de dites coses han manat la present certificatoria esser feta y aquell liurada e segellada en lo dors del segell menor de lur offici"r2o.

Pel privilegi de vitualles, atorgat pel rei Marti, quan un vaixell passava per acf, si hi havia necessitat, estava permès prendre la càrrega de forment pagant després l'import de la seva vàlua $i$ aixo no era considerat com a una practica corsària tot i que ocasionava moltes incidencies. De la nau de Leonard Grimaldo de Niça, anomenada Santa Maria de la Victoria, el dia 7 de gener de 1519 es donava fe que es descarregaren 1.000 quarteres d'ordi brut que foren posades en botiga. Aquest ordi havia estat

\footnotetext{
${ }^{17}$ ARM, EU, 25, fol. $228 \mathrm{r}$.

"ARM, EU, 25, fol. 216 r.

${ }^{19} \mathrm{ARM}, \mathrm{EU}, 25$, fol. $248 \mathrm{r}$ i $249 \mathrm{r}$.

${ }^{20} \mathrm{ARM}, \mathrm{EU}, 26$, fols. $8 \mathrm{r}$ i $15 \mathrm{v}$.
} 
carregat a Oristany en major nombre per Guillem Muntells de Caller per a consignar a Ausias Leonard a Valencia. El divendres 20 de febrer del mateix any el dit Leonardo comparegué davant els jurats dins la sala inferior de la casa de la Universitat i digue: "Senyors jo so arribat de Ayvissa ab la mia nau la qual per temps ha surt della lo cap Blanch, aporta tre-centes sinquanta quarteres de ordi que se levat en Ayvissa..". Com que interessava comprar-ne li concediren 1 sou d'ajuda per cada quartera $i$ el dit Leonard acceptà i es comprometé a efectuar la descàrrega. I encara el 19 de març descarregaria una partida de 267 quarteres i 3 barcelles d'ordi brut ${ }^{21}$.

Altre tipus de document en aquest sentit són els d'asseguretat de forment, o sia el compromis per part d'un mercader d'aconseguir dit cereal, 0 altres productes, i transportar-los a Mallorca en un termini previament fixat. Vet acr alguns exemples:

Marquino Valeda, mercader de Vilafranca de Niça pero ara resident a la vila d'Alcúdia, el 14 de març de 1493 assegurava al lloctinent Joan Aimeric, cavaller, a Gaspar Bordils, un dels jurats del Regne i a Domingo Bofill, doctor en dret regint la cancelleria del lloctinent, dur en el port d'aquella vila 1.000 quarteres de forment bo novell $\mathrm{i}$ rebedor del territori de Provença les quals prometia aportar ad festum Carnis primorum salvo justo impedimento. El patro del gale 6 nomia Beson de Marsella ${ }^{22}$.

Mallorca era terra de redistribucio de mercaderies. Pel que fa a Niça el 14 de desembre de 1467 el mercader mallorqur Bernat Spia assegurava 50 liures sobre 80 quintars de cuiram bovf barbaresc que carregaria en la nau de Joan Pérez de Curusio per portar a la ciutat de Niça ${ }^{23}$. El dia 27 del mateix mes Pau Pardo, altre mercader, assegurava 100 lliures sobre 6 feixos de cuiram de bou en els que hi havia 120 cuirs de Barbaria; dit cuiram s'embarcaria en la nau de Martl de Rala, biscal, causa exportandi in terra Nicie sive de Niça $a^{24}$.

Altres informacions provenen dels guiatges. En aquests consta expressament la petició per a que els sia concedit una mena de salconduit,

\footnotetext{
${ }^{21}$ ARM, EU, 29, fols. 5 r , 21 r, 25 v. i 59 v-59 r.

${ }^{22}$ ARM, Prot. P-388, fols. $78 \mathrm{r}-79 \mathrm{r}$.

${ }^{23}$ ARM, Prot. C-200, fol. 168 v.

${ }^{24}$ ARM, Prot. C-200, fol. 147 v.
} 
de garantia, pel fet d'haver aportat vitualles a Mallorca, cosa que no sempre queda reflectida en els de simple certificatoria. El salconduit afectava al patró de la nau, altres passatgers i mercaderies. A tall d'exemple, amb informacio directa 0 indirecta sobre Niça o niçards, en serien els següents:

El 7 d'octubre de 1502 els col.lectors del vectigal de la mercaderia certificaven als jurats que Lambert Capell, niçard, era arribat el dia anterior en el port de la Ciutat amb la seva barca i havia aportat vitualles co és avellanes, nous e castanyes. Pretenia, doncs, alegrar-se del guiatge de vitualles tant per ell com per la barca, mercaders i passatgers vinguts amb la dita barca aixl com les robes i mercaderies que hi transporta ${ }^{25}$.

D'altra banda, els col.lectors del dret del vectigal de la mercaderia $i$ altres drets de mar donaven fe com en el present dia, que era el 17 de febrer de 1503, havia arribat en el port el navili de Yvardo Durmea, nissard, en el que havia aportat i volia descarregar castanya blancha, aros, fesols y mell. I per dits comestibles volia aconseguir el guiatge de vitualles atorgat al present Regne ${ }^{26}$.

El niçard Dionis de Berameu amb la seva barca havia aportat vitualles, és a dir, sèmola i forment. Per tal motiu demanava el consegüent guiatge i aixo ocorria el dia 11 de març de $1504^{27}$. En altra ocasio, 21 de febrer de 1506, era Honorat Genovard de Vilafranca de Niça qui es trobava en el port de la present Ciutat $a b$ un seu barxot o carracho en el que havia duit prop de 1.500 quarteres de forment del qual ja havia descarregat bona part en terra. Volia disposar del guiatge per la seva barca, robes, mercaderies, passatgers i mariners. El forment era del mercader genoves Cosme de Corsio ${ }^{28}$.

Vicenso de Bimaya, niçard, en la seva barca surta en el port de la ciutat de Mallorca, havia lliurat vitualles com arros, llegums, fruites seques i peix salat per la qual cosa estava en disposicio de demanar el corresponent guiatge $i$ ho feia el 28 de gener de $1508^{29}$.

\footnotetext{
${ }^{25}$ ARM, EU, 23, fol. 142 v.

${ }^{26} \mathrm{ARM}, \mathrm{EU}, 23$, fol. $222 \mathrm{v}$.

${ }^{27}$ ARM, EU, 24, fol. 4 r.

${ }^{28}$ ARM, EU, 24, fol. $106 \mathrm{v}$.

${ }^{29}$ ARM, EU, 25, fol. 268 r.
} 
Priam de Villalonga, receptor del vectigal de la mercaderia, autentificava el 13 de gener de 1510 que era en el port Peyro Infant, niçard, amb la seva barca i que havia transportat vitualles com arrossos, castanyes $i$ avellanes entre altres coses i per tant sol.licitava li fos concedit el guiatge ${ }^{30}$.

Jordi Pont, col.lector del vectigal de la mercaderia i Antoni Busquets col.lector de l'imposit del moll garantien als jurats que Joan Marti, patró de la barca anomenada Sant Salvador de Vilafranca de Niça, havia descarregat en el dia present, o sia el primer de març de 1513, 26 sacs, 10 caixes i 2 botes de nous i 7 sacs de castanyes. Volia amparar-se en el guiatge de vitualles ${ }^{31}$.

Joan Durmeya de Niça, arribat acf amb la seva barca de nom Sant Joan Baptista, requeria li fos concedit el guiatge de vitualles per haver aportat 21 sacs d'arros i 40 quarteres de castanyes, pomes i anous per valor de més de 100 lliures. La peticio data del dia 10 d'octubre de $1515^{32}$.

De vegades els documents de guiatge no esmenten el tipus de mercaderies aportades aci sien o no vitualles. El que si especifiquen clarament és l'interès en obtenir el salconduit per estar i negociar a l'illa per més temps. Val a dir que les autoritats tenien present que aixo era important per conservacio $i$ augment de la negociacio mercantil. Un exemple podria ser:

El primer dia de setembre de 1517, el lloctinent assegurava la persona i béns del niçard Bartomeu Langier, notxer de la nau de Joan Martl surta en el port de la present ciutat per a que pugui estar en la nau, davallar, eixir a terra, negociar, comerciar i tornar-se. Durant la vigencia del guiatge no podrà ser arrestat, empatxat, convengut, detingut ni inquietat civilment ni criminal. La contrapartida és que no sia tengut civilment ni criminal a homes de la terra ni hagi comès crim de lesa majestat, d'heretgia, sodomia, ni falsedor de moneda. El lloctinent manava que tots elśs oficials reials observin dit guiatge sota pena de 200 lliures al fisc reial aplicadores $^{33}$.

\footnotetext{
${ }^{30}$ ARM, EU, 26, fol. 5 r.

${ }^{31} \mathrm{ARM}, \mathrm{EU}, 27$, fol. $6 \mathrm{v}$.

${ }^{32}$ ARM, EU, 27, fol. 237 v.

${ }^{33} \mathrm{ARM}, \mathrm{AH}, 426$, fol. $141 \mathrm{r}$.
} 
Semblants guiatges es concediren durants aquests anys a: Joanot Ubirichaga, domiciliat a la ciutat de Niça i patró de la nau anomenada Santíssima Trinitat (16 febrer 1492) ${ }^{34}$; Paulo Ramon, niçard i patro de galio (24 abril 1514) 35 ; Jaume Durmea, niçard i patro de galeassa (2 abril 1515) $)^{36}$; Joan, niçard, patró de barca (9 octubre 1515) ${ }^{37}$; Pirotxo Martí, niçard, patro de nau (4 setembre 1521$)^{38}$; Francisco Fenar de Niça, patró de galio (19 octubre de 1521) ${ }^{39}$; altra vegada Pirotxo Martl (25 febrer $1522)^{40}$. De manera puntual, idd, s'acordava concedir guiatges als mariners de Niça o de Vilafranca els quals es beneficiaven de la protecció de les autoritats locals ja des de 1396, segons Macaire.

En altres ocasions el guaitge no era per un termini breu com eren els casos anteriors, sovint sis dies, sino que tenia major abast. En aquests casos no era el lloctinent qui el concedia sino el propi monarca. El 25 de febrer de 1487, in villa del Viso, Ferran el Catolic signava una carta que enviava a tots els vassalls i als germans Tomàs i Jordi Gastadengo, ciutadans i mercaders de la ciutat d'Alba del marquesat de Montferrato i als germans Bartomeu, Domingo i Antoni del Posso, ciutadans de Niça del ducat de Savoia. Mitjançant aquest document donava llicencia per a que tots ells in regnis nostris stare venire et negociari possitis. Assegurava als predits cum omnibus familiis et familiaribus ac factoribus en les ciutats de Valencia, Barcelona, Sićlia i Mallorca ${ }^{41}$.

En el mateix sentit, de bell nou, es concedia un guiatge a Antoni del Posso juntament amb Arciu Valleca també mercader niça

rd. El rei en una carta datada a Barcelona el 5 de novembre de 1491 explicava que tenia bona pau i aliança amb el duc de Savoia $i$ els vassalls d'ambdós podien anar i comerciar en els regnes i terres d'un i altre. Per tal motiu concedia guiatge als niçards esmentats, que de present residien a la ciutat de Mallorca, perque poguessin "star, trestajar i negociar en lo dit

\footnotetext{
${ }^{34}$ ARM, Prot. P-412, fols. 20 r-20 v.

${ }^{35}$ ARM, AH, 426, fol. 198 v.

${ }^{36}$ ARM, AH, 426, fols. 125 r-125 v.

${ }^{37}$ ARM, AH, 426, fols. 127 r -127 v.

${ }^{38} \mathrm{ARM}, \mathrm{ARM}, \mathrm{AH}, 426$, fol. $177 \mathrm{r}$.

${ }^{39}$ ARM, AH, 426, fol. 178 r.

${ }^{40}$ ARM, AH, 426, fol. 182 v.

${ }^{4}$ ARM, LR, 77, fols. 84 r-86 v. i L.R. 78, fols. 138 r-140 r.
} 
regne e altres regnes e terres nostres com de present feu". Per a més seguretat atorgava salconduit "que liberament salva o segura ab totes les mercaderias, or, argent, pecúnias, robes e altres qualsevol béns vostres pugau e puga cascu per si star en la dita ciutat de Mallorques e altres qualsevol ciutats, viles e lochs de nostres regnes e terras e de aquells a la ciutat de Nissa e altres terres

del dit ill. Duch trestajar e comerciar" amb qualsevol nau, galeassa o navili que no sia d'enemics, tant per mar com per terra. La duracio del guiatge o salconduit era a beneplàcit del rei, en aquest cas sis mesos, i després de la seva revocació calia com

unicar-la als interessats directament 0 a la casa on vivien o amb crida pública pels llocs acostumats de la Ciutat. Alhora, el rei manava a tots els oficials reials que complissin amb el disposat en la dita carta ${ }^{42}$.

Entre altres aspectes del comerç niçard cal considerar els problemes que se'n derivaven i que ocasionaven problemes com el pagament de la lleuda o els actes de corsarisme i pirateria.

En relació al comerç dels niçards es suscità un problema envers el pagament de la lleuda que era una tarifa duanera. El 30 d'octubre de 1491, Ferran el Catolic des de Barcelona enviava una carta en la que exposava que els niçards de costum pagaven 1 diner per lliura. Empero Gaspar Tomàs que rebia la dita lleuda i que fou lloctinent del procurador reial "cum auctoritate ac potestate dicti officii ut asseritur interit nisardos predictos distringere et forrciare ad solvendum quinque denarios pro qualibet libra", la qual cosa provocava gran dany i perjudici als niçards. El consol va recorrer al rei per a que provels de remei ${ }^{33}$. Val a dir que de Niça s'importava fusta i lli, sobretot.

Els actes de corsarisme i pirateria eren pràctiques molt freqüents especialment a la Baixa Edat Mitjana a les aigües del mar balear i la documentació se'n fa resso. De niçards com a protagonistes, ja sia actius ja sia passius, en consten alguns casos.

La sagetia genovesa patronejada per Francisco Griffa (1471) i que anava a Sardenya, arribada a Porto Petro, prengué la caravel.la del mercader mallorquf Joan Bartomeu, a qui feriren i robaren les mercaderies,

\footnotetext{
${ }^{42}$ ARM, LR, 76, fols. 5 r-5 v.

${ }^{43}$ ARM, LR, 75, fols: 205 v-206 r.
} 
el patró de la qual era Andreu de Niça. Tals actes es practicaven malgrat ser considerats contra l'equidat, la justícia i rompre la pau existent entre el rei i els genovesos. I aixo que ambdues embarcacions en un principi havien acordat fer el cam juntes los dits patrons per anar ab maior seguretat de males gents ${ }^{44}$.

El dia 5 de novembre de 1487 els jurats enviaven una missiva al monarca $i$, entre altres coses, deien que el volien advertir que, pocs dies abans, dues naus de biscaïns de Joan Pérez que eren en aquest port envestiren a una nau de niçards que amb les seves mercaderies venia cap aci $e$ han la presa aixi com a altres naus. Li demanaven procuràs posar solució al respecte perque la mercaderia per causa dels cossaris e males gents no.s pot sostenir ${ }^{\wedge}$. I no es podia oblidar que el comerç era base fonamental de l'estructura economica illenca.

El mercader Rafel Vidal, un dels defenedors de la mercaderia, es dirigia al lloctinent el diumenge 28 de juny de 1489 amb els següents termes: en els dies proppasats els germans Felip i Peyro Infant "tenint navilis e exercits de piràticha natura diversament depredant $e$ frustrant per la mar les robes e mercaderies", el dit Peyró havia presa una barca de Mart de Leura. Suplicava fes tot quant fos per a que s'impartís justícia pel be de la re pública tenint en compte que aquests atropells estorbaven el comerç i aquest "segons comuna opinió e vera sentencia dels doctors per la negociatio mercantil stan provahit a les necessitats humanes specialment en les ciutats maritimes que.s pot dir aliment natural de aquelles sens lo qual no poden haver comoda sustentacio"46.

A finals de segle l'activitat corsària sembla intensificar-se. Des de Barcelona el rei, el 31 d'octubre de 1492, enviava una carta dirigida als lloctinents, balles, procuradors, veguers, justícies $i$ altres oficials en els regnes de Valencia, Sicnlia, Sardenya, principat de Catalunya, Mallorca i illes adjacents amb el següent contingut: revocació dels guiatges dels niçards. Segons explicava el monarca, Pere Riera de la ciutat de Mallorca querellosament li havia exposat que el passat 8 d'abril trobant-se en Bartomeu Jofre de la ciutat de Niça amb el seu galió comerciant en el port de la ciutat de Mallorques, prestà sagrament i homenatge en mans i poder

\footnotetext{
${ }^{4}$ ARM, AH, 680, fols. $70 \mathrm{v}-71 \mathrm{v}$.

${ }^{45}$ ARM, AH, 683, fols. 95 r-96 r.

${ }^{46}$ ARM, SU 41, fols. $43 r-44 r$.
} 
del lloctinent general en virtut del qual s'obligava i prometia que no dampnificaria vassalls ni amics ni confederats del nostre rei. Ans si feia el contrari fos hagut per traidor i trencador de sagrament. Empero envestI al dit Riera pirdticament $a b$ lo dit

seu galeo, a finals de juliol, i el va prendre davant l'illa d'Eivissa aix com tambe la seva carabel.la carregada de diverses robes i mercaderies posant en terra a dit Riera. Aquest ha demanat al rei proveir de degut remei de justícia sobre el fet. Era per aquest motiu que el rei manava sota pena de 1.000 florins d'or que els oficials reials prenguessin tots els béns i navilis de niçards o de vassalls del duc de Savoia, senyaladament el navili i persona del citat Jofre i complices seus que fossin trobats en les jurisdiccions de cadascun i que no atorgassin cap guiatge als niçards ni a altres vassalls del dit duc. Fins i tot el rei revocava tots els guiatges ja atorgats fins aclarir el problema de Pere Riera ${ }^{47}$.

El divendres 16 de novembre de 1492 el lloctinent Pere de Sant Joan notificava que els mercaders de les ciutats de Valencia, Barcelona i Mallorca havien rebut grans danys y tots dies reben per diversos cossaris jenovessos $e$ nisarts i per aixo el rei havia deliberat que li fossin tramesos pels jurats i consols de la mercaderia dues persones expertes i habils per intervenir sobre la manera de trobar solució al tema. Els interessats calia que ho comunicassin a la Casa de la Universitat per després procedir a la designació per a tal encarrec ${ }^{48}$.

El 1492, sense indicar dia ni mes, els jurats trametien una carta al rei $\mathrm{i}$ exposaven que de les terres de Savoia, signantment de la ciutat de Niça, arribaven navilis amb robes en nom e veu de mercaderia e de gent mercantill. Empero alguns habitadors d'aquella armaven navilis i altres vaixells i arribaven piraticament com si fossin d'enemics. Entre ells s'esmenten un tal Forgosa i Peyró Infant. La súplica s'encaminava a reparar els danys causats en persones i mercaderies víctimes dels esmentats niçards ${ }^{\text {t9 }}$.

Amb tot, Niça no era el port del Sud de França amb més relacions amb Mallorca, ni tampoc Marsella, sinó que serien els del Rossello, Arles o Aigues-Mortes. Malgrat aixo, la relació comercial entre aquella ciutat i la

\footnotetext{
${ }^{47}$ ARM, LR, 78, fols. 149 v-150 r.; ARM, SU, 41, fols. 191 v-192 r.

4ARM, EU, 19, fol. 227 r.

${ }^{49} \mathrm{ARM}, \mathrm{AH}, 684$, fols. 76 r-76 v.
} 
de Mallorca existia i la presencia d'un col.lectiu de niçards, sobretot mercaders, a la nostra illa ho deixa ben pales.

\section{APĖNDIX}

Miscel.ldnia de dades referides a niçards en la ciutat de Mallorca baixmedieval:

1463-V-22. Referencia a un tal Jaume de Niça entre els mariners del bergantı de Martl Gonçalbo. Prengué part en la presa de botı de llaüts d'homes rebels al rei en les mars de Tarragona en el marc de la guerra civil catalana ${ }^{\text {so }}$.

1464-V-5. Referencia a una nau de nissards "qui stech en conserva de les gualeres en lo port de Maho de mentre que lo dit lochtinent hi tench lo siti. Es tracta del siti de Menorca durant la guerra civil catalana ${ }^{51}$.

1470-V-28. Joan Vayrat, mercader de Niça, pro nunc residens in civitate Maioricarum, anomenava procurador al fuster de Ciutat Gabriel Molins, per exigir en nom seu 40 sous que li devia Víctor Doto, argenter ${ }^{32}$.

1472-V-4. Joan Bolitxer, pescador, acordava un contracte amb Antoni, niçard, causa piscandi. Les clausules són les propies d'un contracte de servei domèstic pero introduint aspectes d'un contracte laboral, és a dir, alimentació i sou, en el qual el propietari li havia de donar menjar i beure a més de 14 lliures. Antoni restava obligat a servir-lo en totes les feines sempre que fossin honestes tant de dia com de nit ${ }^{33}$.

1476-III-4. Lluis Burgarello, mercader niçard habitant a la ciutat de Mallorca, reconeixia que el donzell Francesc Axelo li havia lliurat 1.200 quartans d'oli clar que li vengue. Li prometia pagar-ne la meitat el proxim

\footnotetext{
${ }^{50}$ ARM, RP, 1208, fol. 94 v.

${ }^{51}$ ARM, RP, 3575, fol. 26 v.

${ }^{52}$ ARM, Prot. C-171, fol. $8 \mathrm{v}$.

${ }^{33}$ ARM, Prot. B-99, fol. 19 v.

Aquest mateix dia el pescador contratava a un altre jove, aquest de 14 anys, Jaume Joan, tambe per a servir-lo en l'ofici de pescar i a qui entregaria 12 lliures.
} 
mes de juliol i l'altra meitat per la festa de Nadal. Un dels testimonis era Tomàs Gastadenguo, també mercader niçard ${ }^{54}$.

1479-X-8. Branquirius Be, mercader oriund de la ciutat de Niça pero ara habitant a Mallorca, anomenava procuradors al mercader Bartomeu Prats i a l'escrivà Joan Ballester perque s'ocupassin de la causa existent entre ell i el mercader Joan Vidalss.

1479-VI-12. Bartomeu Cranadossa, mercader niçard ara resident en la present Ciutat, dies pasats havia venut a Gabriel Vilapriu, mercader de Ciutat, una calanera per preu de 205 florins d'or que foren pagats de comptants. Pero essent la dita calanera en el port de Trapani patronejant-la Pere Cabessa havia estat denunciada per Francr Sbert el qual pretenia que era seva i que li havia estat furtada i per aixo demanava que fos presa per la Cort. S'iniciava un conflicte entre els interessats ${ }^{56}$.

1480-III-16. Carta dels jurats a Gaspar Despes, virrei en el regne de Sicflia exposant que per la flaca anyada i manca de blat s'havia acordat enviar el ballener d'Andrea de Niça, que era en el present port, per anar a carregar formenten aquella illa. Els jurats comentaven que "aprés de Déu no tenien altra sperança sino en la ajuda e remey que per medi del dit balaner o fforment de aquell nos serà donada". Suplicaven que els permetés sense triga carregar el dit ballener ${ }^{37}$.

1480-VII-30. Bartomeu del Posso o Potzo, mercader de Niça pero ara resident a Mallorca, anomenava procurador al seu germà Antoni per tal de cobrar algunes quantitats que li eren degudes. En el mateix document hi ha una referencia a un tal Miquel Claret, mercer de la ciutat de Niça. Els testimonis foren Arcis Valeta i Pere Pavia, mercaders de Niça pero en el moment habitants a Mallorca ${ }^{58}$.

1480-VII-31. Arcis Valeta, mercader niçard, anomenava procurador a Pere Pavia, també mercader de Niça, per cobrar quantitats que li eren degudes ${ }^{39}$.

\footnotetext{
"ARM, Prot. P-428, fols. 20 v-21 r. i P-371, fol. 28 r.

ss ARM, Prot. B-106, fols. 53 v-54 r.

${ }^{36}$ ARM, Prot. M-489, fols. 35 r-35 v.

${ }^{57}$ ARM, AH, 681, fols. $105 \mathrm{v}-106 \mathrm{r}$.

SoARM, Prot. B-99, fol. 123 r.

99 ARM, Prot. B-99, fold. 124 r-124 v.
} 
1480-VII-31. Bernat Amades, gerrer, reconeixia deure a Pere Pavia, mercader de Niça, 47 lliures i 10 sous per compra de 10 quintars de lli de Niça net de tares a rao de 5 lliures i 15 sous el quintar el qual volo causa navigandi vel vendendi. Prometia pagar abans del proxim gener i com a garantia obligava els seus béns. Un dels testimonis era Arć́s Valeta, mercader niçard ${ }^{60}$.

1481-VIII-31. Llú́s Valeta, mercader i ciutadà de Niça, venia al paraire Martf Cavaller dos esclaus de nacio de turcs, un anomenat Alf i l'altre Amet, de 30 anys. El preu convingut fou de 156 lliures $^{61}$.

1481-IX-4. Lluís Valeta, mercader de Niça, venia a Pau Bestard, habitador de la parroquia de Robines, un esclau de nacio de turcs anomenat Mostaffa, de 20 anys, pel preu de 67 lliures i 10 sous $^{62}$.

1483-III-12. Antelm Deraxa nacionis nisorum sive de Nissa, es col.locava amb el pescador Joan Bolaix per servir-lo in arte vestra a més del servei domèstic pel perfode d'un any. Dar-li de menjar, beure, calçar i vestir eren les obligacions del pescador a més de 13 lliures i 10 sous a l'acabar el termini indicat ${ }^{3}$.

1484-III-20. Rafel Carasnagui oriund de la ciutat de Niça, menor de vint-i-cinc anys pero major de disset, es col.locava amb el cirurgia Miquel Forns per un perfode de quatre anys a partir del dia present "causa serviendi vobis et botigie vestre in negociis exercicio ac operibus illius" tant de dia com de nit sempre que allo que li manas fos honest. Al mateix temps el contracte indicava "me teneamini in arte seu oficio vestris instruere in super sitis... mihi legere de arte cirurgici accomodareque libros gracia andrendarum a vobis lectionum"64.

1484-VIII-14. Bartomeu del Posso i el seu germà Antoni, mercaders niçards pero habitants a Mallorca, estaven obligats a Bernat Cotoner, ciutada, per certa quantitat de cuiram bovl per valor de 250 lliures $^{65}$.

\footnotetext{
${ }^{60}$ ARM, Prot. B-99, fol. 123 v.

${ }^{61}$ ARM, Prot. C-166, fol. 83 r.

${ }^{\circ 1}$ ARM, Prot. C-166, fol. 84 r.

${ }^{63}$ ARM, Prot. M-266, fol. $10 \mathrm{v}$.

${ }^{4}$ ARM, Prot. 379, fols. $60 \mathrm{v}-61 \mathrm{r}$.

${ }^{65}$ ARM, Prot. C-205, fol. 73 v.
} 
1491-IX-16. Portas Malet, mercader niçard, anomenava procurador a Simo Puig, cansídic, per exigir deutes ${ }^{66}$.

1491-XII-31. Nicolau Pere, "mercator Nicie pro nunc degens in civitate Maioricarum causa mercancie, venia al mercader i ciutada Antoni Dureta una esclava anomenada Joana, de nacio de negres de Montdebarques, de vint-i-cinc anys d'edat pel preu de 40 lliures. En el document hi ha una referència a un tal Simo de la Costa, mercader de Niça pero ara a Mallorca causa mercancie ${ }^{67}$.

1492-III-21. Caterina, lliberta i abans esclava de Bernat de Brossa, ciutada, prometia pagar a Polo Vischa, mercader niçard, 14 lliures i 3 sous per un pitxer de plata "quod in domo vestram me illam custodiente deperdictum fuit". Prometia pagar dins un any, un terç de quatre en quatre mesos. El dit Brossa per estima a Caterina es constituïa en fiança. El niçard reconeixia que si el pitxer compareixia li tornaria els diners ${ }^{68}$.

1502-XII-10. Francesc Despuig, ciutadà, venia al llibreter Jaume Irdis i a Antoni de Niça, mariner, la seva calanera o barca surta en el port anomenada Santa Maria, alias de nom la Fadiga, juntament amb totes les seves xarxes, arreus, i armes. El preu convengut fou de $\mathbf{4 0 0}$ lliures. Jaume Irdis reconeixia a Antoni de Niça com a patro de la dita calanera pero no hi podia posar ningu sense el seu consentiment a no ser el seu gendre Salvador Mas et non alit ${ }^{69}$.

1503-VII-30. Margalida que fou muller de Salvador Mas, mariner, i filla d'Antóni deNiça, es col.locava en segon matrimoni amb Joan Mates, mariner. La dot ascendia a 100 lliures $^{\text {to }}$.

1517-VI-26. Tomàs Asquer, llibreter, fill d'Antoni Asquer, ciutadà i mariner de Niça, feia testament davant el notari Mateu Moranta. Anomenava marmassors a la seva mare Margalida ja vídua i al seu oncle Bartomęu Aurich, ciutadà de Niça. Elegia sepultura a l'església de Santa Reparata de Niça a la tomba on reposava el seu pare. Deixava: 1 florf a l'església de Santa Reparata, 1 florf als pobres de Sant Llàtzer de Niça, 1 florı a

\footnotetext{
${ }^{6}$ ARM, Prot. P-386, fol. 148 r.

${ }^{67}$ ARM, Prot. C-172, fols. $191 \mathrm{r}-191 \mathrm{v}$.

ARM, Prot. C-240, fols. 32 r-33 r.

${ }^{60}$ ARM, Prot. M-591, fol. 174 r.

${ }^{70}$ ARM, Prot. M-592, fols. 74 v-75 r.
} 
l'hospital general de Sant Eligi de Niça, 1 florl a l'església de Sant Jaume d'on era parroquia, 2 ducats d'or per misses a Santa Reparata, 2 ducats al seu oncle Bartomeu, 10 florins al seu consobrino Bernat i 5 ducats als seus nebots fills de la seva germana Margalida i de Florenç Ramusat. Declarava com a hereva la seva mare. Els testimonis eren: Francesc Gaspar Despuig, donzell; Miquel Viciat i Jeroni de Monte, mercaders i ciutadans de Niça; Humberto Gui, mercader i ciutada de Burgo in Brescia ; Benet de Prats, llibreter; Pere Font i Jeroni Ballester, escrivans de Mallorca ${ }^{71}$.

1465-III-12. Rafel Carle, mercader de Niça pro nunc vero residens in civitate Maioricarum, anomenava procurador a Pere lo barber, patró de llaüt de la ciutat de Valencia. Entre els testimonis figurava Bartomeu del Posso, mercader de Niça habitant a la ciutat de Mallorca ${ }^{2}$.

\section{RÉSUMÉ}

L'île de Majorque, au milieu du bassin de la Méditerranée occidentale, a été témoin du passage des navigateurs, spécialement des marchands, lesquels depuis l'Antiquité ont traversé la Mare Nostrum. Cette situation de port important a exercé une influence extraordinaire sur la vie de la cité de Majorque et dans l'île. Quant à l'époque du Bas Moyen Age le commerce constituera une des activités économiques fondamentales. Il ne faut pas s'étonner, alors, que il y ait des marchands de maintes et différentes provenances, surtout des régions méditerranéennes, qui fassent escale à Majorque et parmi eux les Niçois.

Quoique les consulats italiens, specialement ceux de Genes ou de Venise, fussent plus nombreux ou remarquables, Nice néanmoins disposait d'un consulat dans la cité de Majorque, ce qui reflete l'importance des relations commerciales qu'il y avait entre les deux ports. La plupart des Niçois s'appliquaient aux tâches mercantiles; quelques uns meme établirent leur résidence définitivement dans la cité de Majorque.

\footnotetext{
"ARM, Prot. M-613, fols. 24 v-25 v.

Sobre aquest llibreter, vegeu Gabriel LLOMPART MORAGUES, Tomds Squer, un librero nizardo en la Mallorca de Carlos V, "Gesammelte Aufsätze zur Kulturgeschichte Spaniens", 32 (Munster 1988), pp. 372-407.

${ }^{n}$ ARM, Prot. C-185, fol. $15 \mathrm{r}$.
} 


\section{SUMMARY}

The island of Majorca, in the middle of the West Mediterranean basin, has been a witness to the passage of navigators, specially merchands who since Antiquity have been crossing the Mare Nostrum. Its role as an important harbour has exerced an extraordinary influence over life in the City of Majorca and over the island. In the late Middle Ages trade was one of the basic economic activities. It is not surprising then that merchands of many different ports of origin, above all from the Mediterranean area, should call at Majorca; amongst them many from Nice.

Although the Italian consulates, specially those of Genoa and Venice, were more numerous or outstanding, Nice counted on a consulate in the city of Majorca, which shows the importance of commercial links between the two places. Most people from Nice devoted themselves to commercial tasks; some of them even established themselves definitively in the city of Majorca. 